9.2\% of patients had variable follow up that requires standardisation. Risk of recurrence is low, however, both cases were malignant.

\section{EPV206/\#481 PREOPERATIVE EVALUATION OF ADNEXAL MASS IN BREAST CANCER PATIENTS}

${ }^{1} \mathrm{~A}$ Ennes* ${ }^{*}{ }^{1} \mathrm{M}$ Wagner, ${ }^{1} \mathrm{E}$ Mayerhoff, ${ }^{1} \mathrm{C}$ Anton, ${ }^{2} \mathrm{~L}$ Leite, ${ }^{3} \mathrm{~L}$ Testa, ${ }^{1} \mathrm{~J}$ Carvalho. ${ }^{1}$ Instituto do Câncer do Estado de São Paulo, Ginecologia E Obstetrícia, Sao Paulo, Brazil; ${ }^{2} A C$ Camargo Cancer Center, Oncologia, São Paulo, Brazil; ${ }^{3}$ Instituto do Câncer do Estado de São Paulo, Oncologia Clínica, Sao Paulo, Brazil

\subsection{6/ijgc-2021-IGCS.277}

Objectives Evaluation of ovarian cysts (OCy) are specially challenging in patients with a history of breast cancer (BC). We aimed to characterize a population of $\mathrm{BC}$ patients submitted to oophorectomy for OCy and establish risk factors for malignant findings on surgical specimen.

Methods All BC patients treated with oophorectomy for OCy between 2008-2021 at a tertiary hospital,were retrospectively reviewed.

\begin{tabular}{|c|c|}
\hline Characteristics & $\mathrm{N}=66$ \\
\hline Median age (range) & $51(27-76)$ \\
\hline \multicolumn{2}{|l|}{ Histology (\%) } \\
\hline Invasive Ductal & $57(86.4)$ \\
\hline Invasive Lobular & $2(3)$ \\
\hline Ductal in situ & $3(4.5)$ \\
\hline Other & $4(6)$ \\
\hline \multicolumn{2}{|l|}{ Staging $(\%)$} \\
\hline 0 & $1(1.6)$ \\
\hline 1 & 10(15.9) \\
\hline 2 & 23(36.5) \\
\hline 3 & 19(30.2) \\
\hline 4 & 10(15.9) \\
\hline Family History Breast Cancer(\%) & 21(31.8) \\
\hline Family History Ovarian Cancer(\%) & $6(9.1)$ \\
\hline Suspected Hereditary breast-ovarian cancer(\%) & $6(9.1)$ \\
\hline \multicolumn{2}{|l|}{ BC subtype(\%) } \\
\hline HR+/HER2- & $45(68.2)$ \\
\hline HER2+ & $11(16.7)$ \\
\hline TNBC & $8(12.1)$ \\
\hline median IOTA-ADNEX/benign risk (IQR), $\mathrm{N}=51$ & $91.2(61-96.6)$ \\
\hline median IOTA-ADNEX/primary malign (IQR), $\mathrm{N}=51$ & $8.8(3.4-39)$ \\
\hline median IOTA-ADNEX/secondary malign (IQR), $\mathrm{N}=51$ & $1.1(0.3-5.6)$ \\
\hline median $\mathrm{CA} 15.3(\mathrm{IQR}), \mathrm{N}=46$ & $21.4(12.9-37.4)$ \\
\hline median CA125(IQR, N=62 & $18.5(11.3-39.3)$ \\
\hline \multicolumn{2}{|l|}{ Ovarian histology(\%) } \\
\hline No cancer & $15(22.7)$ \\
\hline Benign & $32(48.5)$ \\
\hline Borderline & $2(3)$ \\
\hline Ovarian cancer & $7(10.6)$ \\
\hline BC metastasis & $10(15.2)$ \\
\hline
\end{tabular}

Results 66 patients were eligible.Characteristics are described in table 1. Most (71.2\%) had no cancer/benign lesions in the surgical specimens of the ovaries, $10.6 \%$ had ovarian cancer, 15.2\% had BC metastasis and 3\% had borderline lesions. Between the no cancer/benign/borderline the median IOTAADNEX/benign was $92.5 \%(I Q R$ 62.6-96.6). Between the ovarian cancer the median IOTA-ADNEX/primary-malign was 83.7\%(IQR 41-89.1). In the metastatic lesions the median IOTA-ADNEX/secondary-malign was $1.5 \%(\mathrm{IQR} \quad 0.3-12)$. The following variables were associated with a greater risk of malign ovarian histology: metastatic $B C$ at diagnosis $(p=0.01)$, ascites $(p=0.004)$, elevated CA125 $(p=0.01)$, elevated CA15.3 $(\mathrm{p}=0.002)$. Table 1 .

Conclusions CA125/CA15.3 are good pre-operative markers, IOTA-ADNEX is a good tool to distinguish bening cysts and OC.

\section{EPV207/\#484 DISPARATE TRENDS IN OVARIAN CANCER IN ASIANS LIVING IN ASIA AND THE UNITED STATES}

${ }^{1} \mathrm{C}-\mathrm{I}$ Liao*, ${ }^{2} \mathrm{E}$ Thayer, ${ }^{3} \mathrm{~A}$ Moon, ${ }^{4} \mathrm{D}$ Wong, ${ }^{5} \mathrm{~A}$ Chan, ${ }^{6} \mathrm{~A}$ Milki, ${ }^{4} \mathrm{~A}$ Francoeur, ${ }^{7} \mathrm{~J}$ Chan. ${ }^{1}$ Kaohsiung Veterans General Hospital, Obstetrics and Gynecology, Kaohsiung City, Taiwan; ${ }^{2}$ University of Massachusetts Medical School, Obstetrics and Gynecology, Worcester, USA; ${ }^{3}$ Stanford University School of Medicine, Obstetrics and Gynecology, Division of Gynecologic Oncology, Stanford, USA; ${ }^{4}$ University of California Los Angeles, Obstetrics and Gynecology, Los Angeles, USA; ${ }^{5} \mathrm{Pal}$ Alto Medical Foundation Research Intitute, Obstetrics and Gynecology, Palo Alto, USA; ${ }^{6}$ George Washington University School of Medicine and Health Sciences, Obstetrics and Gynecology, Washington DC, USA; ${ }^{7}$ California Pacific Medical Center, Obstetrics and Gynecology, San Francisco, USA

\subsection{6/ijgc-2021-IGCS.278}

Objectives To describe trends in ovarian cancer among native Asians and in the United States.

Methods Data were obtained from the United States Cancer Statistics (USCS) and Taiwan Cancer Registry of Taiwan Health and Welfare Data Center from 2001 to 2017. SEER*Stat 8.3.9, Joinpoint regression program 4.8.0.1, and Excel were used to calculate incidences and trends.

Results From 2001 to 2017, ovarian cancer incidence rose in native Asians (Taiwan) at a rate of $2.1 \%$ per year $(p<0.001)$ while they fell in US Asians at $1.2 \%$ per year $(p=0.026)$. Native Asians had increasing incidences of cancers of all cell types, with the fastest growth seen in rare ovarian tumors such as carcinosarcoma $(6.4 \%$ per year, $p=0.003)$, clear cell carcinoma $(6.2 \%$ per year, $\mathrm{p}<0.001)$, and sex cord stromal $(5.7 \%$ per year, $\mathrm{p}<0.001)$. Interestingly, although the overall incidence of ovarian cancer decreased in US Asians, the incidence of clear cell carcinoma rose $2.1 \%$ per year $(\mathrm{p}<0.001)$ in this group. In 2017, the peak age ovarian cancer in native Asians was 55-59 years old, younger than the peak in US Asians at 75-79 years old.

Conclusions From 2001 to 2017 the ovarian cancer incidence in native Asians rose, driven by increases in rare tumors, while the incidence in Asians living in the US declined, leading to $25 \%$ more cancers among native Asians than US Asians. 